\title{
Chicken Production, Marketing Status, Constraints and Opportunities in Tero-Afta District of Jimma Zone, South West Ethiopia
}

\author{
Kumilachew Achamyelh \\ Department of Agricultural, Economics Division, Ethiopian Institutes of Agricultural Research, Jimma Agricultural Research Centre, Jimma, \\ Ethiopia
}

Email address:

taye.kume@gmail.com

To cite this article:

Kumilachew Achamyelh. Chicken Production, Marketing Status, Constraints and Opportunities in Tero-Afta District of Jimma Zone, South West Ethiopia. International Journal of Economic Behavior and Organization. Vol. 9, No. 3, 2021, pp. 71-75.

doi: 10.11648/j.ijebo.20210903.14

Received: July 24, 2021; Accepted: August 12, 2021; Published: August 24, 2021

\begin{abstract}
Poultry is the largest group of livestock species in the world in which chickens largely dominate the flock composition. The poultry sector in Ethiopia can be characterized into three major production systems based on selected parameters like breed, flock size, housing, feeding, health, technology, bio-security and others. Though This observations focused on a complete 120 families had been decided on and personally interviewed to gather the facts. The data have been analyzed by use of the statistical package (SPSS). the primary constraints detects village chicken production inside the observe location had been sickness, predators, loss of proper fitness care, bad feeding, housing, poor watering, and shortage of marketplace access replacement of indigenous chickens by means of exceptional hen breeds is also found inflicting dilution of the indigenous genetic assets. Newcastle disorder (NCD) changed into identified as economically essential fitness constraint that hinders chicken production and productiveness within the take a look at location. The results indicates that inappropriate coping with of chicken and a lack of Agricultural extension service (47\%), loss of production substances (35.3\%), the hazard of predators $(16.7 \%)$ and fear of theft $(10 \%)$, housing troubles, Lacks infrastructure, low supply of logistics which includes transportation, failure to mobilize the network, Lacks incents for exceptional sports, low supply of logistics which include transportation, failure to mobilize the network, Lacks incents for special activities.
\end{abstract}

Keywords: Tiro Afta, Multistage, Challenges, Opportunities

\section{Introduction}

\subsection{Background}

Ethiopia has about $60 \%$ of the whole bird populace of East Africa, which incorporates neighborhood, special, and hybrid chook breeds [2]. Ethiopian chickens population is expected to be approximately 56.53 million out of which $94.3 \%$, $3.21 \%$, and a pair of $.49 \%$ of the populace belong to indigenous, hybrid and unusual breeds, respectively [2]. Rearing of chickens can create extra profits except intake of eggs that may help to enhance dietary protection. [11] it is extensively been said that chickens are the foremost widely stored cattle species in the developing world. [8] Indigenous chickens are cosmopolitan in most the rural and consistent with-urban areas where they play the vital role of earnings technology and food production. The indigenous chickens are higher to conform to the hard surroundings; they're tolerant of the many sicknesses and are exact brooders, and however they may be negative in their reproductive and efficient overall performance [2]. Consequently, to decorate the performance of the neighborhood chickens, the special chickens are imported which includes White and Brown.

Leghorns, Rhode Island Red, New Hampshire, Cornish, Australorp Light Sussex [5]. They were crossed with local chickens to enhance the genetic potential of indigenous breeds. Even if, Ethiopia owned huge chicken flock; there are various factors like diseases, predators, lack of proper healthcare, feed source and poor marketing information that hinder the productivity of the chickens in most areas of the 
country $[1,9]$. Among the above obstacles, diseases are the most constraints incriminated for the reduction of total numbers and compromised productivity [3]. Currently, one of the extension options is that the use of full packages jointly with improved exotic breeds that are better in terms of productivity. The Extension Department of the Ministry of Agriculture of Ethiopia has shown more preference and interest to the utilization of the Rhode Island Red breed that might be serving as a dual-purpose for both egg and meat production [1]. Additionally, the Fayoumi breed has been imported with the expectation of higher productivity, better adaptation and disease resistance than the other exotic breeds within the rural setting of Ethiopia [4] reported that the exotic chicken like Brown, Bovans Brown, Potchefstroom Koekoek and Sasso were distributed to smallholder farmers in some parts of the country.

Therefore, the objectives of this study is, to assess the status and production performance of exotic chickens, and to debate the most constraints of improved or exotic chickens production and marketing management in Tiro Afta district, Jimma Zone, Southwest Ethiopia.

\subsection{Objective}

1) To summarize and identifies the main problem of the chicken production system and marketing in the Jimma zone Tero-Afta District.

2) To analyze and demonstrate field observed with chicken production technology.

3) To show poultry production and marketing linkage in Jimma zone Tero-Afta District.

\section{Methodology}

\subsection{Description of the Study Area}

Geographically, the town is located at $7^{\circ} 40^{\prime} 00^{\prime \prime}$ N latitude and $36060^{\circ} 00^{`} \mathrm{E}$ longitude. Jimma area might be divided into escarpment and alluvial plains. Jimma town administrative is located in the southwestern part of Oromia National Regional State Jimma town is $350 \mathrm{~km}$ far from the capital Addis Ababa in the southwest of the country. Jimma zone consists of 21 districts Southwestern Ethiopia, Jimma Zone is one of the four zones known by high coffee production supply. Jimma Zone lies between latitudes $7^{\circ} 15^{\prime} \mathrm{N}$ and $8^{\circ} 45^{\prime} \mathrm{S}$ and longitudes $36^{\circ} 00^{\prime} \mathrm{E}$ and $37^{\circ} 40^{\prime} \mathrm{E}$. The zone generally lies in altitude ranging between 900 and 3334 More than half of the zone (52\%) lies between 1500 and 2000 mails. As a result, the Jimma zone enjoys several types of agro-ecological zones from moist to dry arid zones. Tiro Afeta is one of the 180 districts. In the Oromia Region of Ethiopia. Part of the Jimma Zon Tiro-Afeta is bordered on the South by Omo Nada, on the west by Kersa, on the north by Limmu Kosa, and on the east by Sokoru. The administrative center of the district is Dimtu. The altitude of this district. Ranges from 1640 to 2800, mountains include Geshe, Haro, Gerbera and Hako Alberti. Perennial rivers include Gilgel Gibe, Busa, Nadi, and Aleltu. A survey of the land in this district. Shows that $26 \%$ is arable or cultivable ( $20.5 \%$ was under annual crops), $8.3 \%$ pasture, $14 \%$ forest, and the remaining $51.7 \%$ are considered built-up, degraded or otherwise unusable.

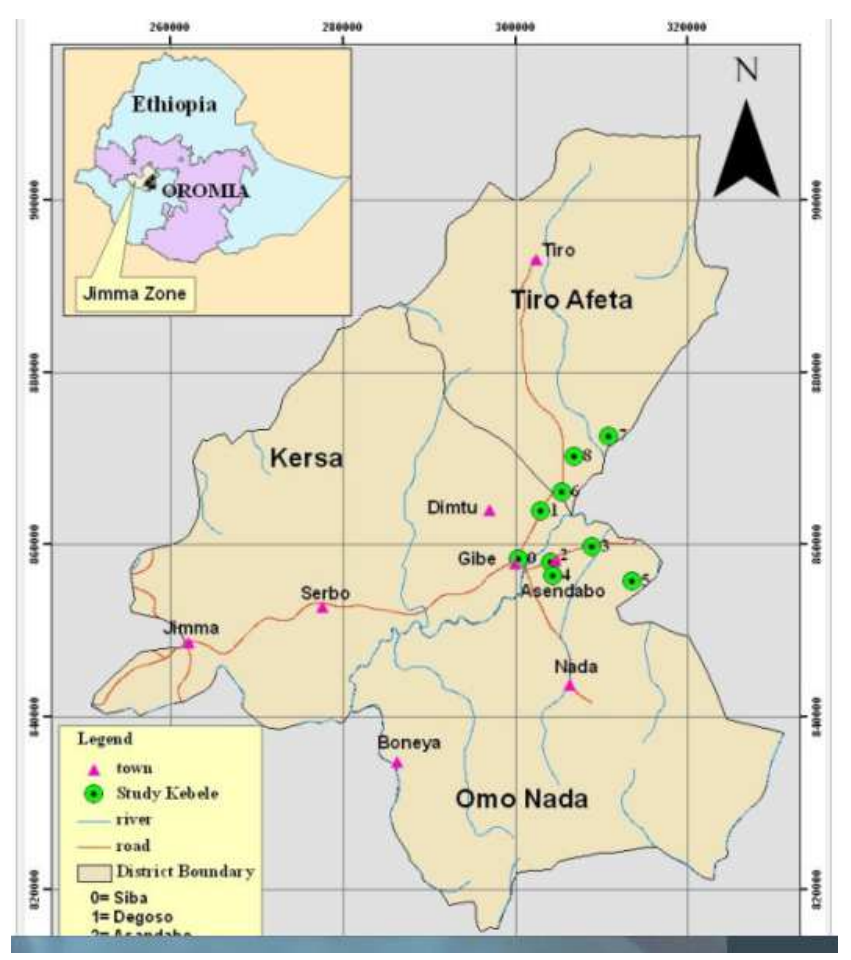

Figure 1. Map of the study area Tiro-Afeta.

\subsection{Data Sampling Procedure}

Our data concerning concentrates on poultry production and marketing problems in the Tiro-Afta districts were collected from two side's i.e. urban agriculture offices and sampled respondents.

\section{Sample Size Interviewed}

From these districts, 4 Kebeles were selected. Purposively depending on experienced farmers in poultry production and representative of the poultry cooperatives. From each Kebele 30 households selected randomly, totally from this district, Primary data was collected from 120 households using a structured questionnaire. Qualitative data also collected using Focus Group Discussion (FGD) and Key Informants (KII). Moreover, secondary data was also collected from the Jimma zone Agricultural office and different published and unpublished documents.

\subsection{Socioeconomics Characteristics of Household}

About $73.3 \%$ of the interviewed farmers were females and $76.7 \%$ of the respondents were fully involved in mixed farming activities as a means of livelihood. The remaining $3.3 \%$ and $20 \%$ of the respondents were engaged in crop and livestock production respectively. The majority of the respondents $(86.7 \%)$ were married and the largest proportion $(83.3 \%)$ of the respondents was within the age group of 31 50 years. About $56.7 \%$ of the respondents About 33.3, 36.7 
and $30 \%$ of the respondents had gone through the primary first cycle (1-4), primary second cycle (5-8) and high school $(9-12)$ education respectively.

Table 1. Sampling Frame of households in each Kebele.

\begin{tabular}{lll}
\hline Poultry Population & Kebeles & Number of Households \\
\hline High $(1855-17051)$ & Dechanadhe & 30 \\
Medium $(1025-1765$ & Kjeloo & 30 \\
Low $(407-1011)$ & Tiyoo & 30 \\
& Regasiba & 30 \\
Total & & 120 \\
\hline
\end{tabular}

\subsection{Major Constraints of Poultry Production and Marketing in the Study Area Diseases}

The results of this study tend to indicate that poultry diseases were widely spread in the study area. About $50 \%$ of the respondents confirmed that occasional and serious disease outbreak results in complete devastation of the flock when accrued [10]. About 30, 26.7, 33.3 and $10 \%$ of the respondents reported infectious coryza, fowl cholera, Newcastle and gumbo row were a disease of economic importance in the study area, respectively. The commonest disease outbreak in the study area is reported to be Newcastle. Most of the time these diseases occur during wet $(60 \%)$ and dry $(40 \%)$ season. This is further by the zonal veterinary experts, all of whom indicated that Newcastle disease is one of the major limitations to poultry production in the study area. A few of farmers in the study area followed a vaccination after a report of disease cases (40\%) and after a certain animal died $60 \%$ ). So based on the above problem, prevention methods like importance of regular pre vaccination, management system was taken by DVM technicians. The results of this study is in line with that of Tesfu (2006) who ranked predation and disease conditions as the major problem of chicken production in Ethiopia [7].

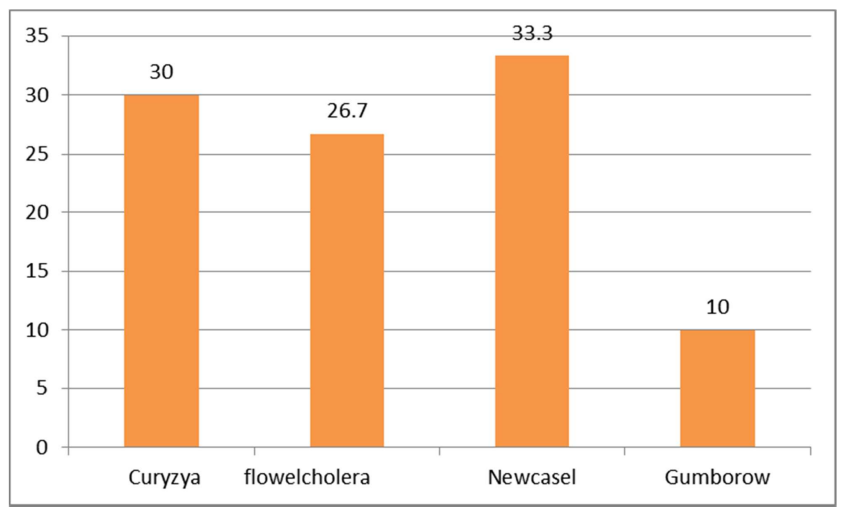

Figure 2. Major diseases affect poultry in the study area.

\subsubsection{Management Practices}

The poultry production system in the study area about $6.7 \%$ (intensive), 72.3\% (extensive) and the remaining is semi intensive. The reason for most respondents used extensive farming system was due to lack of construction materials for their shed (35.3\%), The participation of respondent in purchase of exotic chicken was few in the study area due to lack of awareness (23.3\%), budget (46.7\%), and low adaptability of the chicken to the area $(30 \%)$. Training was provided on Effects of Poultry Manure on Compost and consequence effect on soil fertility and crop yield Poultry manure effect on environment if it is disposed at every place.

\subsubsection{Housing System}

There was only $33.3 \%$ of the respondent manages their chicken and $23.3 \%$ having a separate house. According to the information generated from the respondents for inappropriate handling of chicken are a lack of Agricultural extension service $(47 \%)$, lack of construction materials $(35.3 \%)$, risk of predators $(16.7 \%)$ and fear of theft $(10 \%)$. Even those respondents who had separate houses $(23.3 \%)$ completely sealed the poultry house with mud $(50 \%)$, lack of perch and lack of ventilation as identified aligned with [12].

So depending upon our result that we have obtained from problem identification through structured questionnaires and field observed through home to home we were tried to address the housing problems in our intervention phase according to the time frame, finance, and some inputs. This result is in agreement with the findings who reported that both in Ethiopia and in Kenya, the majority of chickens are housed either in family dwellings or in the kitchens [6].

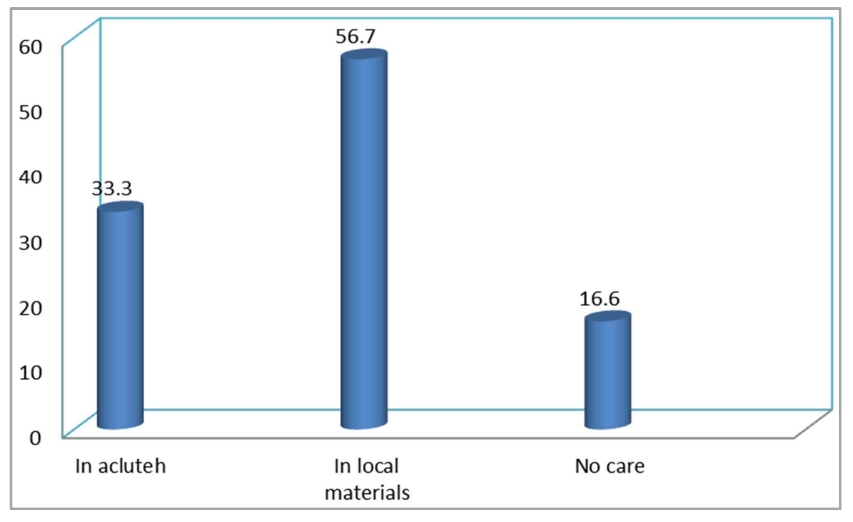

Figure 3. Handling and storage of eggs.

\section{Input and Output}

\subsection{Inputs}

Inputs were: Community mobilization, providing training on poultry production and marketing, preparing feed, Constructing hay box and integrate indigenous knowledge of stakeholders. Community mobilization was done by cooperatively working with agricultural offices of the study area and specifically with developmental agents of the werdas.

\subsection{Outputs}

These are the specific products or services, which is expected to produce. They were the end results they lead to the achievement of immediate objectives. Some outputs were awareness of the poultry production system, management system (feeding, watering, housing system, egg storage system and etc. There was also there is a change in behavior 
or the participant's adoption techniques and methods or changes in their practices. Examples of a change in actions include application and actual use of applied knowledge; adoption of new or improved skills; adoption and use of new methods or improved technologies of poultry production and marketing management.

\section{Marketing System}

There is no formal poultry and poultry product marketing channel in the Tiro-Afta Wereda and informal marketing of live birds and eggs involving open markets are common throughout the Wereda. The farmers directly sell their chicken to consumers and/or to small retail (traders) who take them to large urban centers. Live chickens and eggs are sold either at the farm gate, small village market (primary market), or at the larger Wereda market (Secondary market in the town). There is an exchange of commodities throughout the week with one regular market day at the center of each Kebele. The results of this study clearly showed that both eggs and chickens pass through different individuals before reaching consumers.

The regular customers of live birds and eggs of the TiroAfta Wereda are shown in About 52.2\% of chickens are collected by retailers and direct consumers. At all the market areas of Tiro-Afta and in most of the cases, the sale and purchase of live chickens and eggs is the responsibility of females indicating that household poultry is a source of selfreliance for women since live bird and egg sales are decided by women, both of which provide women with an immediate income to meet household expenses. Unstable price and demand seasonality are the problems of egg and live chickens marketing in the study area.

According to the results of this study, there is variation in the price of eggs and live birds attributed to disease outbreaks, time of incubation, and holidays and festivals. The price of live birds further varies based on body weight, feather color, comb type, age and sex. Producers get better prices both for live birds and eggs during holidays and festivals. Live birds and eggs are carried by foot and pieces of cloth, plastic shopping bags, and baskets are used to transport eggs to the market in Tiro-Afta Wereda, all of which could result in breakage and deterioration in egg quality. Moreover, the live bird market of Tiro-Afta Wereda is characterized by small unhygienic selling space and a lack of shelter, feed, and water. This result agrees with that of [13] who reported that in Ethiopia, indigenous birds and eggs could be transported over longer distances to supply urban markets which results in quality deterioration. Both eggs and live birds are transported either on foot or using public transportation along with other bags, sacks of grains, bundles of firewood etc. About $57.1 \%$ of the respondents stored the market eggs on the nest. The remaining $18.5 \%$ and $5.6 \%$ of the respondents stored in the basket and in the iron dish respectively. On average the market eggs were stored for 12.15 days before being sold. In this study, all of the respondents stored eggs for more than 15 days before incubation. About 29.4\%, 50.6\%, and $20 \%$ of the respondents stored the eggs from 15 to 20,21 to 26 , and 27 to 35 days before incubation respectively.

\section{Risks/Constraints}

\subsection{Constraints}

Lacks of infrastructure, low supply of logistics such as transportation, failure to mobilize the community, Lacks incents for different activities. Intervention/Remedy for Constraints/Risk, Closely working with Agricultural experts, farmers, researchers, trainees, government and nongovernmental organizations, cooperatives and private institutions to get incentive needed for program implementation purpose, Using locally available materials for different demons.

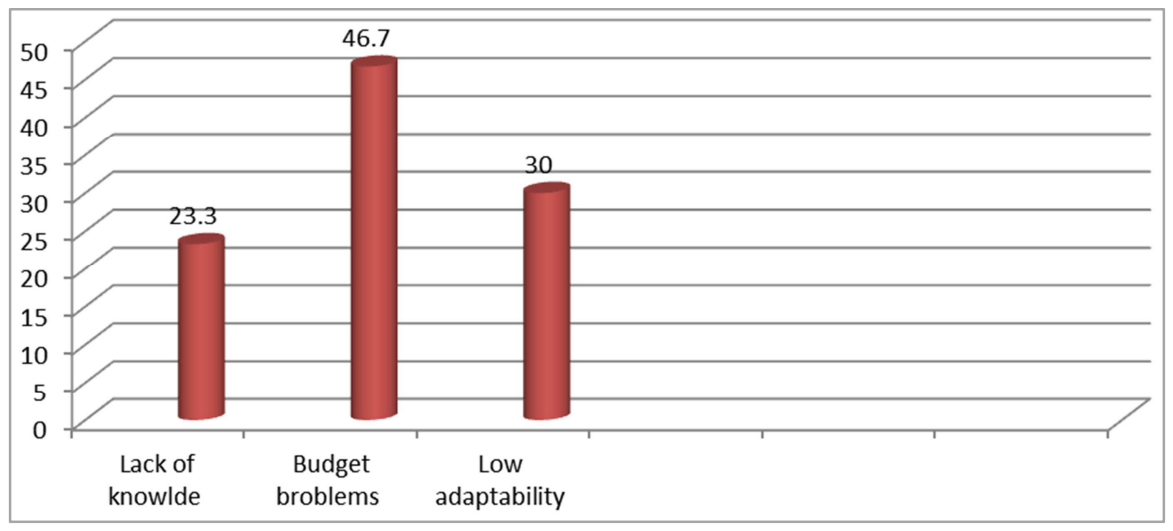

Figure 4. Major Constraints to purchase chicken in in the study area.

\subsection{Opportunities}

The major opportunities of poultry production identified in the present study were:

A high price for eggs at the market center due to the shortage of egg supply in the market.

The increase in demand for eggs due to the increase in number of hotels, restaurants and pastries in study area. An emerging middle-class urban dwellers with higher income and more buying power. 
Credit service availability by the micro finance institution.

Availability of experts at woreda level for the technical support and extension services.

Availability of veterinary services in the werda with a minimum veterinary drug price at veterinary drug store.

\section{Conclusion}

The study where conducted to identify the main problem of the chicken production system, analyze and demonstrate field observed with chicken production technology and to figure out poultry production systems marketing situations, management structure i.e. housing technology, feeding system, watering system, health management especially prevaccination, egg storage, and handling system. And also their knowledge and skill on was developed as they work cooperation with each other and input supply like the importance of exotic chicken was identified. in Jimma zone Tero-Afta District.

\section{Recommendations}

Continuous awareness, identification, and prioritization of the problem are a crucial point which should be important in the study area concerning poultry production and marketing by employing Agricultural Extension and Jimma urban agriculture experts.

To join different kinds of innovations which maybe cannot be owned by individual farmers; group work is an indispensable way of solving farmer's common problems.

To increase the knowledge and skill level of the farmers; attention has to be given for their indigenous knowledge.

Giving practical training supported by demonstration is more accepted to the future continuation of the innovation with the farming community if the budget required for the demonstration participates with different NGOs.

For the future promotion of the study, the farmers' collaboration with another stakeholder: such as the Urban Agricultural Development Office Agricultural Extension, and NGOs, Agricultural Research centers and with the farmer is important.

Implementing a strong linkage between smallholders and private input suppliers in Jimma Zone on Poultry.

Advise farmers by closely interact with private drug shop owners in Jimma as well as Addis Ababa particularly by identifying the type of inputs they sell for smallholder farmers.

Making linkage between Micro finances such as Oromia Saving and Credit Association $\mathrm{n}$ with individual farmers.

\section{References}

[1] Ashenafi, H., Tadesse S. Medhin, G. and Tibbo M., 2004. Study on Coccidiosis of scavenging indigenous chickens in central Ethiopia. Trop. Anim. Hlth. Prod. 693-701.

[2] Alemneh, T. and Getabalew, M., 2019. Exotic chicken production performance, status and challenges in Ethiopia. Int $J$ Vet Sci Res, 5 (2), pp. 039-045.

[3] Mohammed, A., 2018. Major Constraints and Health Management of Village Poultry Production in Ethiopia: Review School of Veterinary Medicine, Jimma University, Jimma, Ethiopia. Journal of Research Studies in Microbiology and Biotechnology, 4 (1), pp. 1-10.

[4] Reta, D., Negussie, D. and Alemu, Y., 2012. Comparative production performance of two exotic chicken breeds under two different feed regimes in three agro-ecologies of central Oromia, Ethiopia-a step forward for distribution or contract rearing of day old exotic chicks under rural setting. Livestock Res Rural Dev, 24 (9).

[5] Tamirat D (2015) Overview and background paper on Ethiopia's poultry sector Relevance for HPAI research in Ethiopia.

[6] Kitaly (1998) and the Resource-Center (2005) who reported that both in Ethiopia and in Kenya, the majority of chickens are housed either in family dwellings or in the kitchens.

[7] Tesfu (2006) who ranked predation and disease conditions as the major problem of chicken production in Ethiopia.

[8] Alexander, D. J., Bell, J. G. and Alders, R. G., 2004. A technology review: Newcastle disease, with special emphasis on its effect on village chickens. USAID (2012) Assessment of Available Birds in Ethiopia 1-4.

[9] Matawork M (2016) Review on Exotic Chicken Status, Production Performance and Constraints in Ethiopia. Journal of Biology, Agriculture and Healthcare 6: 2224-3208. Link: https://bit.ly/2NR7cR6

[10] Poultry farming generates substantial risk for emergence of novel infectious diseases. It is now the most important source of animal protein for the human population and the industry is changing rapidly (FAOSTAT, 2019).

[11] Mengesha, M., Tamir, B. and Dessie, T., 2011. Village chicken constraints and traditional management practices in Jamma District, South Wollo, Ethiopia. Livestock Research for Rural Development, 23 (2), pp. 30-37.

[12] Mohamed, A., Hailemariam, S., Gebremedhin, G. and Gebevew, K., 2016. Challenges and opportunities of small scale poultry production system in Jigiiga Zone, Somali regional state, Ethiopia. Pou. Fish Wildl. Sci, 4 (1), p. 144. 